\title{
A Study of CD44 Positive Cancer Cells in Epithelial Ovarian Cancer and their Correlation with P53 And Ki67
}

\author{
Ketaki Kar ${ }^{1}$ Suman Ghosh ${ }^{2}$ Anup Kumar Roy ${ }^{2}$ \\ ${ }^{1}$ Department of Pathology, Midnapore Medical College \& Hospital, \\ Midnapore, West Bengal, India \\ 2Department of Pathology, Nil Ratan Sircar Medical College \& \\ Hospital, Kolkata, West Bengal, India \\ J Lab Physicians 2021;13:50-57.
}

Address for correspondence Suman Ghosh, MD, 44 D Vivekananda Road, Kolkata, West Bengal, 700006 India (e-mail: dr_sumanghosh@rediffmail.com).

\begin{abstract}
Context Epithelial ovarian carcinomas are one of the most common lethal gynecological malignancies. There is no specific symptom or biomarker for detection of this malignancy in early stage. So, the advanced stage, nature of frequent recurrences, and resistance to chemotherapies make it very difficult to deliver proper treatment to patients. Efforts are on to identify the presence of cancer stem cell by using a specific biomarker in epithelial ovarian cancer in the early stage.

Objectives This study aims to identify the CD44 positive cancer cells in epithelial ovarian carcinoma of different histopathological types. It also intends to correlate the expression of CD44 with the expression of p53 and Ki67.

Materials and Methods Sections from diagnosed specimens of ovarian epithelial neoplasm had been fixed in $10 \%$ formalin and embedded in paraffin, and they were used for immunohistochemical (IHC) staining for CD44, p53, and Ki67, using a peroxidase kit with mouse monoclonal antibodies. Then, the slides were evaluated for both tumor cell percentage and intensity of immunoreactivity.

Statistical Analysis Chi-square had been used to find the significance of study. Significance level was considered at $p$ value $<0.05$

Results In this study, 40 patients were included in a period of one and a half years. The present study suggested that the levels of CD44 expression were increased in epithelial ovarian cancer compared to borderline tumor. CD44 was positively correlated

\section{Keywords}

- epithelial ovarian cancer

$-\mathrm{CD} 44$

$-p 53$

$-\mathrm{Ki} 67$ with the ki67 expression and tumor grade. High-grade serous, mucinous, and endometrioid tumors were associated with high CD44 expression. Positivity of CD44 was found significantly higher in case of positive status of p53 ( $z=3.65 ; p<0.0001)$. Conclusion We can correlate CD44 positive cancer stem cells with grade of ovarian carcinomas, but for prognostic significance and therapeutic applications, more corroborative and multicentric works in this field are needed. CD44 can be targeted for therapy in recurrent and resistant cases of ovarian cancer.
\end{abstract}

published online

February 22, 2021
DOI https://doi.org/

10.1055/s-0041-1724235 ISSN 0974-2727.
(C)2021. The Indian Association of Laboratory Physicians.

This is an open access article published by Thieme under the terms of the Creative Commons Attribution-NonDerivative-NonCommercial-License, permitting copying and reproduction so long as the original work is given appropriate credit. Contents may not be used for commercial purposes, or adapted, remixed, transformed or built upon. (https://creativecommons.org/licenses/by-nc-nd/4.0/).

Thieme Medical and Scientific Publishers Pvt. Ltd. A-12, 2nd Floor, Sector 2, Noida-201301 UP, India 


\section{Introduction}

Epithelial ovarian tumor is very common throughout the world. ${ }^{1}$ Ovarian carcinoma is the second most common cancer burden in the gynecological field. ${ }^{2}$ It is the seventh leading cause of cancer deaths globally (age standardized mortality rate is $4.0 / 100,000)^{2}$ and is also the most lethal gynecological malignancy due to its late presentation. The causes are nonspecific symptoms, inefficient screening markers at early stage, and metastasis. The combination of surgery and chemotherapy is initially effective, but recurrence rate is high due to its resistance in chemotherapy. Approximately $70 \%$ of primary ovarian cancer patients develop recurrent tumor within 18 months of receiving first-line treatment. ${ }^{3}$ Hence, it is a challenge to the gynecologist to detect these cases earlier and offer effective therapeutic modalities to treat these cases. The overall survival of patients depends upon histological type, stage, grade, and local and distant metastasis. Five-year relative survival rate for epithelial malignancy is 92 and 30\% in localized and distant metastatic cases, respectively. ${ }^{4}$

Ovaries have three cell lines, namely, surface epithelial cells, sex cord stromal cells (including granulose, theca, and hilar cells), and germ cells (oocytes). ${ }^{5}$ Because of these florid types of cellular composition, it is most prone to develop malignancies of different origin, namely, epithelial, mesenchymal, sex-cord stromal, germ cell, metastatic, etc. Approximately $85 \%$ ovarian malignancies are of epithelial origin. ${ }^{6}$ Six histological types of ovarian epithelial cancers have been described-serous, mucinus, endometrioid, clear cell, Brenner, and seromucinous. ${ }^{3}$ The cell of origin of epithelial ovarian cancer has been debated for many decades. It is diverse for different histological types. ${ }^{4}$

It is well-established at present that these epithelial ovarian carcinomas maintain an effective population of cancer stem cells that are responsible for resistance to therapeutic procedure in some cases, and these population of cancer stem cells also sustain progression of tumor. ${ }^{7}$ Therefore, efforts should be given to identify the cancer stem cells in ovarian tissue samples by immunohistochemical markers. In many studies, the reason behind recurrence is said to be the presence of cancer stem cell (CSC). In previous years, many research works had been performed in search of origin and heterogeneity of ovarian epithelial cancer. In many literatures, they are designated as CSCs or tumor initiating cells (TICs). ${ }^{7}$ They can give rise to the tumor and spread to new areas, developing recurrences. Among the stem cell markers CD44, CD117, CD24, CD133, Bmi-1, ABCG2, and aldehyde dehydrogenase (ALDH) were discovered from different ovarian cancer patients. ${ }^{8}$ CD44 is a transmembrane glycoprotein that acts as a cell adhesion receptor. It is involved in a variety of cellular processes like cellular growth, survival, differentiation, and migration. ${ }^{9}$ It is also known as HCAM, Pgp- 1 , Hermes antigen, and lymphocyte homing receptor. As CD44 is a cell surface receptor for hyaluronate, it may have a role in regulating the interaction of cells and extra cellular matrix and, subsequently, cell migration. ${ }^{9,10}$ As most of the works did not include patients from third world countries including India and particularly so the eastern region of our country, this study aims to review the findings of other researches to see whether expression of CD44 is effective in the same way in our population, and to correlate their expression with histological type of epithelial ovarian cancers and the expression of p53 and Ki67.

Cellular proliferative status may reflect the tumors' potential for proliferation. Ki67 is a cell proliferative marker. It presents in nucleus in all stages (G1, S, G2, and M) of actively dividing cells and absent in resting cells. ${ }^{11}$ The expression of Ki67 in ovarian carcinoma is varied, depending upon histological type, stage and grade. Important prognostic factors for ovarian carcinoma progression are stage of disease, age at diagnosis, histological type and grade, ploidy, and the amount of residual disease after primary surgery. ${ }^{12}$ In recent studies, Ki67 has been identified as an important prognostic factor. So, in this study, the associations of Ki67 with stage and grade were evaluated. P53 is a tumor suppressor protein associated with various cellular functions like cell cycle progression, DNA repair, senescence, and apoptosis. ${ }^{12}$ Two types of p53 have been described, one is wild type and other is mutated $\mathrm{p} 53$. Wild type has very short half-life and cannot be detected in cells. ${ }^{13}$ Mutated p53 is accumulated in cells and detected by immunohistochemical (IHC) staining in diseased cell. Mutated p53 is associated with more than 50\% of cancers.

This study aims to identify cancer stem cells in epithelial ovarian malignancies using CD44 as a novel marker, in order to correlate the level of CD44 expression with histological type of epithelial ovarian cancer and correlate the expression of CD44 with that of p53 and Ki67. This will help early detection of CSCs in epithelial ovarian tumors as well as predict their progression.

\section{Materials and Methods}

\section{Tissue Specimens}

An institutional-based, cross-sectional observational study was conducted in a tertiary care center of West Bengal in the Department of Pathology in collaboration with Department of Gynecology \& Obstetrics, Nilratan Sircar Medical College \& Hospital from January 1, 2018 to June 30, 2019. The work was initiated after obtaining ethical clearance from Institutional Ethical Committee and informed consent from the study population. Patients attending Gynecology and Obstetrics OPD of Nilratan Sircar Medical College \& Hospital and diagnosed clinically as having ovarian cancer, operated upon, and subsequently sent for histopathological examination in Pathology Department were included in the study. Laboratory investigation and parameters included history taking, clinical examination and USG findings, histopathological examination using hematoxylin and eosin (H\&E) staining, staging (International Federation of Gynecology and Obstetrics [FIGO]), grading, and IHC study with CD44, p53 and Ki67 markers. Reporting was done by trained histopathologists. Exclusion criteria included indeterminate histopathological entity, part of the whole specimen received in the Department of Pathology and Chemotherapy treated patient. Samples of all the cases were sent to the Pathology 
Department for histopathological examination on fulfilling the inclusion and exclusion criteria. All tissue samples were collected in $10 \%$ buffered formalin and processed for routine histopathological examination. Grossing and reporting of specimens suggestive of ovarian carcinoma were conducted according to College of American Pathologists (CAP) protocol. ${ }^{14}$ Five micrometers thick sections from formalin-fixed, paraffin-embedded blocks were cut and stained with H\&E for histopathological diagnosis.

\section{Immunohistochemistry (IHC)}

The samples which were positive for epithelial ovarian malignancy by histopathology would be further studied with IHC markers, and the positivity of IHC expression reported using standard procedure and scoring pattern .Correlation of CD44 expression with respect to histological type, grade and stage of the cancer as well as correlation of p53 and Ki67 expression with respect to histological types, grade, stage, and CD44 expression were studied.

For IHC staining, $3 \mu \mathrm{m}$ thick sections from formalin-fixed, paraffin-embedded tissues were taken on poly L lysine-coated slides. IHC was done manually using rabbit monoclonal antibody and the steps mentioned in the kit supplied were followed. A semiquantitative evaluation was done, which was based on the staining, the intensity, and the distribution, using the immunoreactive score. ${ }^{15}$ CD 44 scoring immunostaining was evaluated in a series of randomly selected five high-power fields (200× magnification) and 100 tumor cells were counted in each field. Staining intensity score was graded as follows: no staining, weak staining, moderate staining and strong staining as scores 0,1,2 and 3, respectively.The staining extent score was graded according to the proportion of positive tumor cells as follows: 0 to $5 \%, 6$ to $25 \%, 26$ to $50 \%$ and 51 to $75 \%$ as scores $0,1,2$ and 3, respectively. The staining intensity score was multiplied with the staining extent score, resulting in the semiquantitative immunoreactivity score that indicated the expression level. Immunoreactivity score, depending on CD 44 expression, was calculated as follows: 0 to 2 considered to be negative, 3 to 5 weakly positive, 6 to 8 moderately positive, and 9 to 12 strongly positive. ${ }^{13,16}$ Respective sections from all the 40 cases were studied by selecting the areas showing good cellularity. A minimum of 1000 cells in at least 10 high power fields per section were counted for Ki67 positivity and expressed as a percentage. Cell showing distinctive brown staining of nuclei and nucleoli were counted as positive cells and sections showing $>20 \%$ were counted as Ki67 positive cases. ${ }^{17}$ Evaluation of paraffin IHC was performed by three reviewers. The distribution of p53 immunoreactivity in surface epithelial tumors of ovary were assessed as negative (less than $10 \%$ are negative cells) and positive (equal or more than $10 \%$ are positive cells). ${ }^{18}$

\section{Statistical Analysis}

For statistical analysis, data were entered in MS excel. For descriptive purposes mean \pm standard deviation (SD), range, and percentage were used. Chi-square had been used to find the significance of study using SPSS-18. Significance level was considered at $p$ value $<0.05$.

\section{Results}

In this study, 40 patients were included in a period of one and a half years. Among the 40 cases of ovarian epithelial tumors, the expression of CD44, correlation with stage and grade along with CD 44 association status with p53 and Ki67 were studied.

\section{Demographics and Histomorphology}

The mean age (mean \pm SD) of the patients was $48.10 \pm$ 12.14 years, with range being 14 to 72 years and median age being 48 years. Most of the patients were with age $\geq 35$ years (90.0\%), which was significantly higher than any other age group $(Z=11.67 ; p<0.001)$. Thus, ovarian cancers were mostly prevalent among the patients with age $\geq 35$ years. We encountered 21 cases of papillary serous cystadenocarcinoma, 6 cases of mucinous cystadenocarcinoma, 4 cases of endometrioid carcinoma, 3 cases of clear cell carcinoma, and 6 cases of serous borderline tumor during the study period ( $\mathbf{- F i g s .} \mathbf{1}$ and $\mathbf{2}$ ). In the distribution of characteristics of tumors as per histological types of tumors, prevalence of papillary serous cystadenocarcinoma (52.5\%) was significantly higher $(Z=5.60 ; p<0.001)$. In this study, most of the ovarian tumors were malignant (85.0\%), which was significantly higher than nonmalignant tumors (15.0\%) $(Z=9.89$; $p<0.001)$. The prevalence of high-grade tumors (64.7\%) was significantly higher than low-grade tumors (35.3\%) $(Z=4.15$; $p<0.001)$. In $61.8 \%$ of the cases, lymphovascular space invasion (LVSI) was positive, which was significantly higher than negative LVSI (38.2\%). In 50.0\% of the cases, omental implant was positive and in rest of the cases, omental implant was negative $(Z=0.01 ; p=0.99)$.

\section{Immunohistochemistry (IHC)}

Out of 40 cases studied, 22 (55\%) cases showed positive semiquantitative immunoreactive CD44 score, while in the rest 18
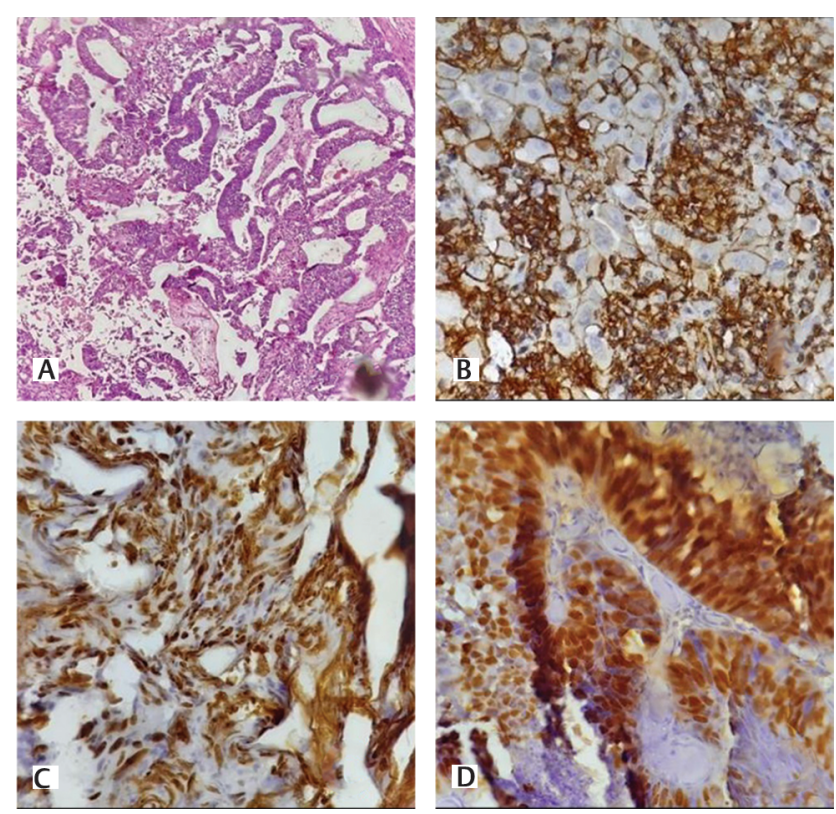

Fig. 1 High-grade serous carcinoma: (A) hematoxylin and eosin (H/E) stain (400X), (B) CD44, (C) Ki67, and (D) p53 immunostaining all showing positivity. 


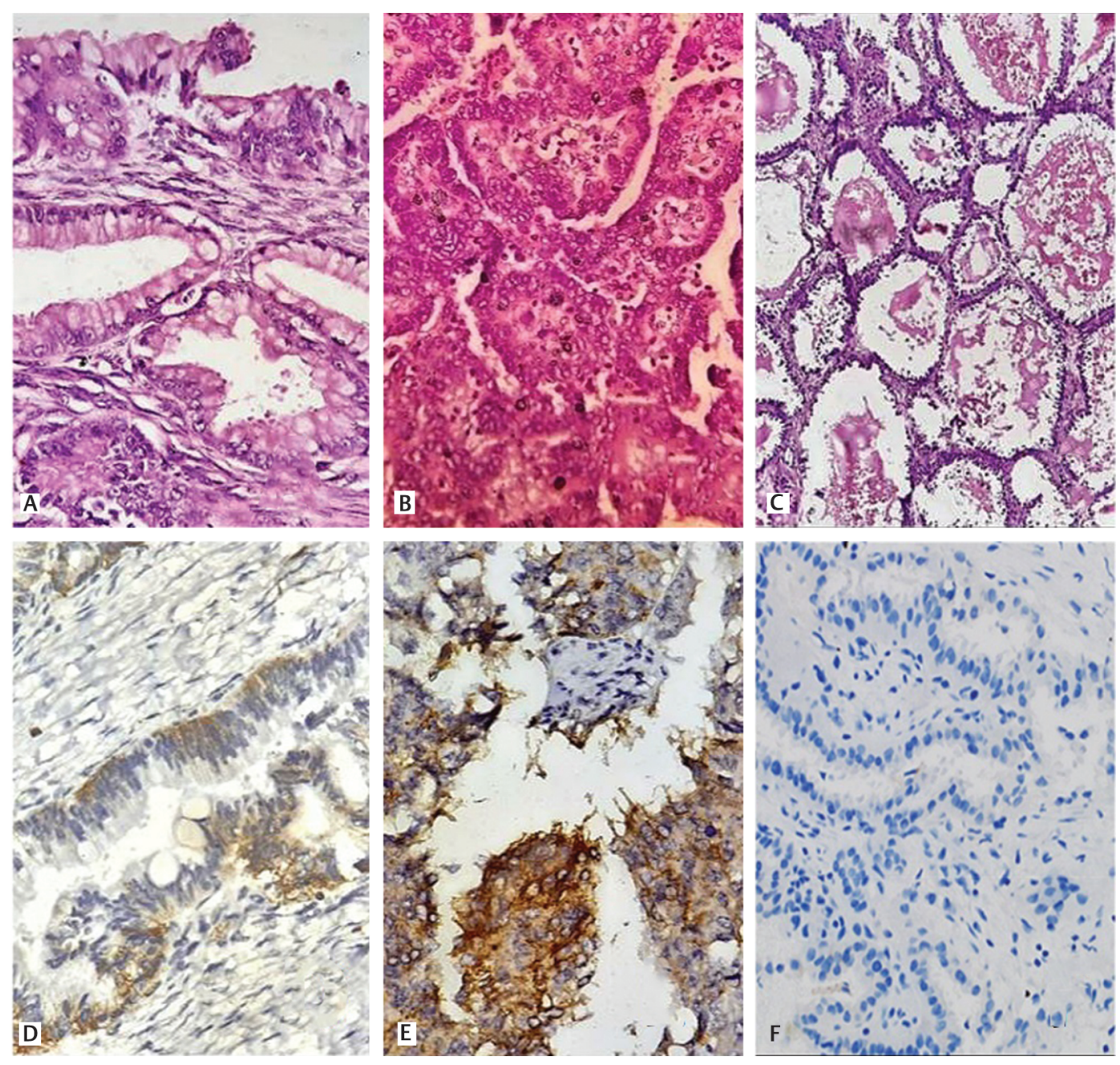

Fig. 2 Histopathological and immunohistochemical examination of various ovarian cancers. Upper panel: HP microphotographs of (A) mucinous cystadenocarcinoma, (B) endometrioid carcinoma and (C) clear cell carcinoma. Lower panel:(D), (E)and(F) CD 44 immunohistochemistry staining of mucinous cystadenocarcinoma, endometrioid carcinoma and clear cell carcinoma, respectively.

(45\%) cases, CD44 score was negative. Although 55.0\% of the cases showed positive CD44 score, which was higher than that of negative cases (45.0\%), it was statistically not significant $(Z=1.41 ; p=0.26)$. Among the positive cases, strongly positive cases were 5 (12.5\%), moderately positive cases 9 (22.5\%), and weakly positive cases were $8(20 \%)$. No significant association was found between status of CD44 and age of the patients ( $p=0.54$ ). However, positivity of CD44 increased with the increasing age of the patients. In our study, out of 11 cases presenting in FIGO stage 1, 6 cases were positive for CD44 positive and 5 cases were negative. Out of 10 cases presenting in FIGO stage 2, 8 cases were positive for CD44 positive and 2 cases were negative. Out of 13 cases presenting in FIGO stage 3, 8 cases were positive for CD44 positive and 5 cases were negative. Chi-square test showed that there was no significant association ( $\mathrm{Z}=5.62, p=0.58$ ) between status of CD44 and FIGO stage of the tumors of the patients. However, positivity of CD44 increased with the increasing FIGO stage of the patients. Out of 22 high-grade tumors in our study, 16 cases were CD44 positive (- Fig. 1) and 6 cases were negative. Of the 12 cases belonging to low-grade group, 6 cases were positive for CD44 and the rest were negative. Positivity of CD44 was found significantly higher in case of high-grade tumors $(Z=3.28 ; p<0.0001)$. High-,grade serous, mucinous and endometrioid is associated with high CD44 expression. Three clear cell carcinomas showed no expression of CD44 (-Fig. 2).

During the study period, 19 cases (47.5\%) showed p53 positivity, while 21 (52.5\%) were p53 negative. Out of 22 CD44 positive tumors in this study, 13 cases were p53 positive and rest 9 cases were negative for p53. Of the 18 cases showing CD44 negativity, 6 cases were p53 positive and rest 12 cases were negative. Association between status of CD44 and status of p53 of the tumors of the patients $(Z=2.63 ; p=0.10$ ) was not significant (-Fig. 3). However, positivity of CD44 was found significantly higher in case of positive status of $\mathrm{p} 53(\mathrm{Z}=3.65 ; p<0.0001)$.

In our experience, 29 cases (72\%) showed Ki67 positivity, while 11(28\%) were Ki67 negative. Out of 22 CD44 positive cases in our study, 19 cases were Ki67 positive and rest 3 cases were negative. Of the 18 cases showing CD44 negativity, 10 cases were Ki67 positive and rest 8 cases were negative. Statistically significant association was found between status of CD44 and status of Ki67 ( - Fig. 4). Positivity of CD44 was found significantly higher in case of positive status of Ki67 


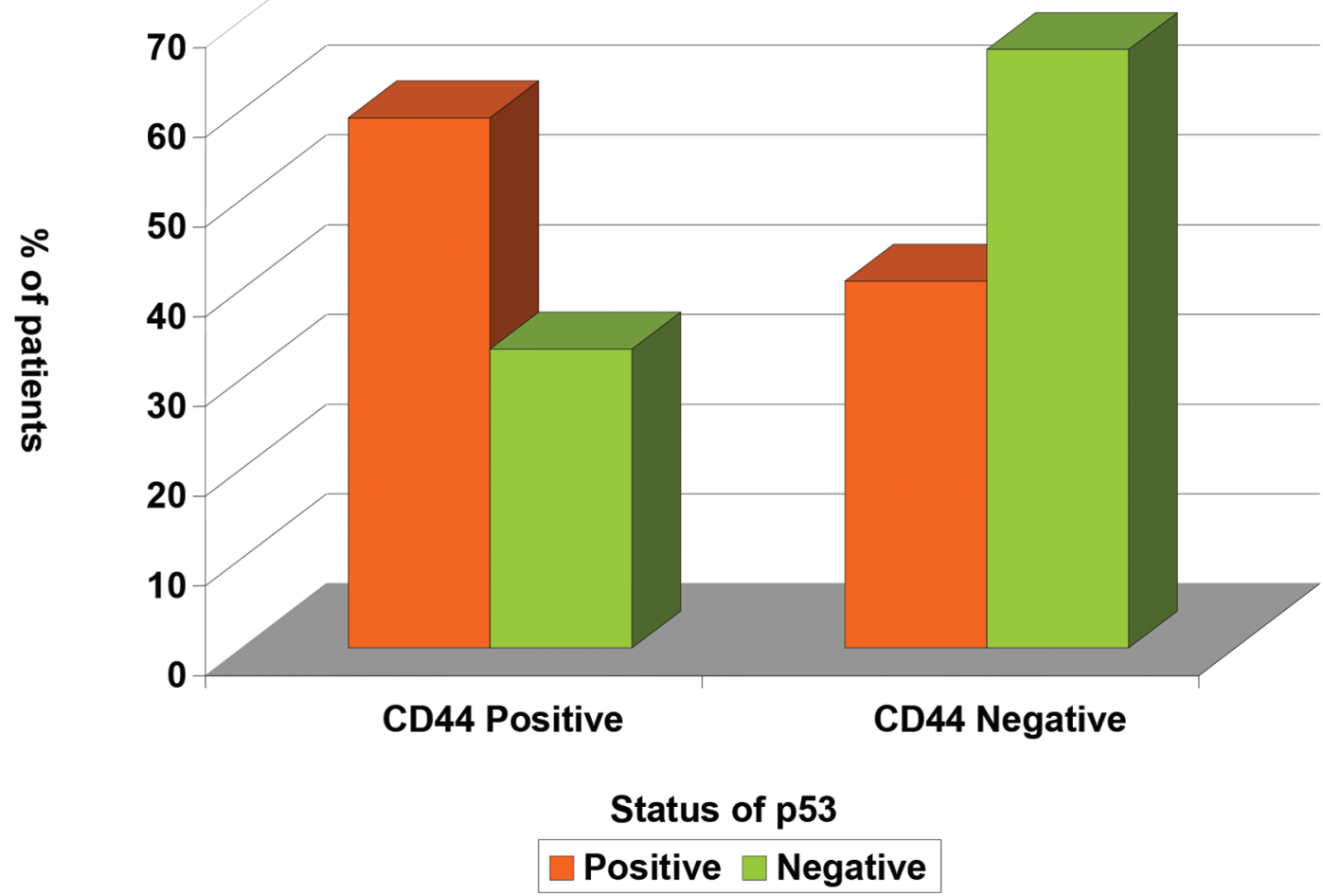

Fig. 3 Association between status of CD44 and status of p53 of the tumors of the patients.

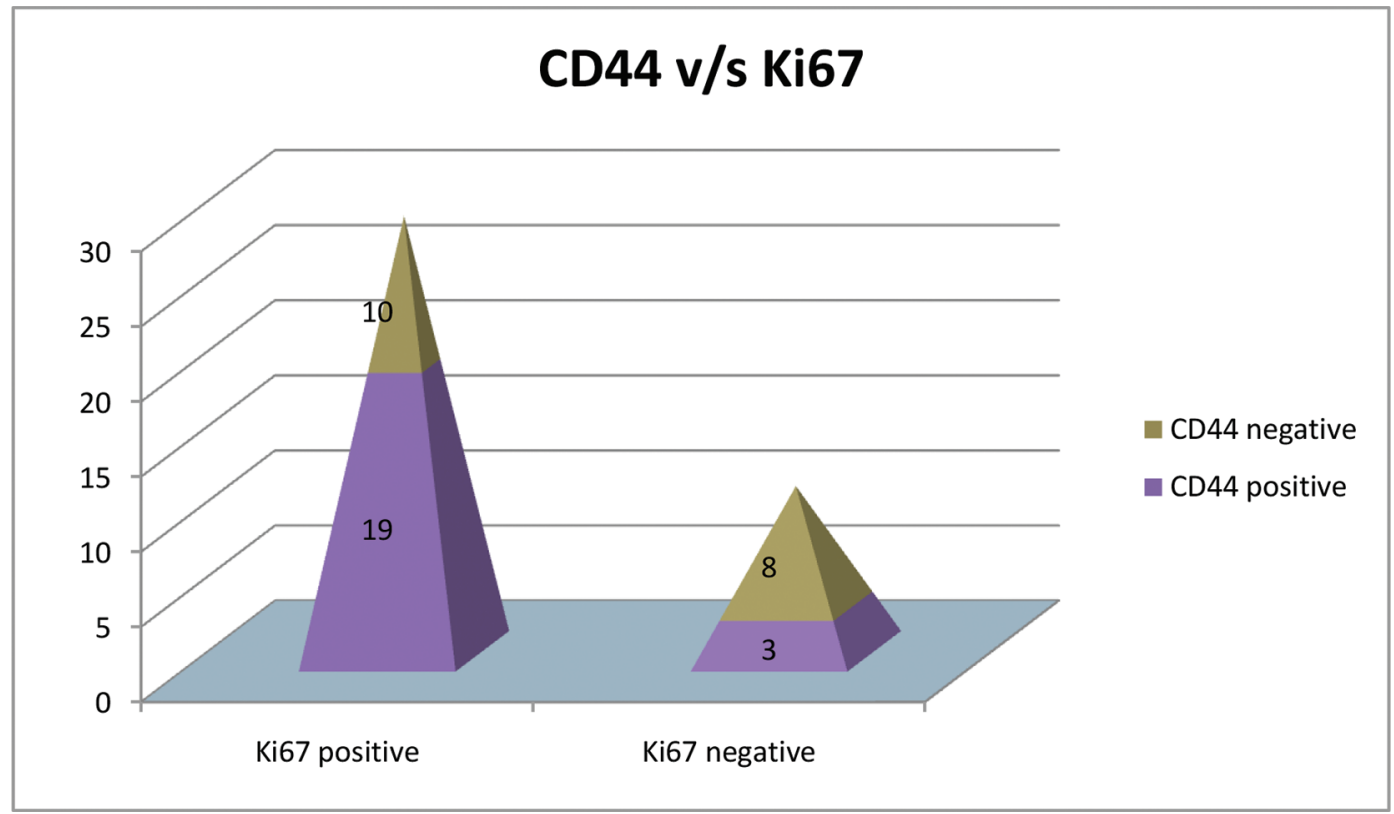

Fig. 4 Association between status of CD44 and status of Ki67.

$(\mathrm{Z}=4.79 ; p<0.0001)$.Positive Ki67 (72.5\%) cases was significantly higher than that of negative Ki67 (22.5\%) cases $(\mathrm{Z}=6.36 ; p<0.0001)$. Out of 22 high-grade tumors in our study, 19 cases were Ki67 positive and 3 cases were negative. Of the 18 cases belonging to low-grade group, 9 cases were positive for Ki67 and rest 3 cases were negative Significant statistical association was observed between grade and status of Ki67 of the tumors of patients (grade vs. Ki67: $p=0.40$ ).

\section{Discussion}

In this study, the range of age is 14 to 72 years and the median age is 48 years. These findings were similar to studies of Mondal et $\mathrm{a}^{19}$ in which the median age was 48 years and Agarwal et $a l,{ }^{20}$ where the age range of patients was from 12 to 80 years and that of Malik et $\mathrm{al}^{21}$ where the mean age at diagnosis was 49.5 years. 
Our study shows $87 \%$ malignant cases in the age group of 35 to 54 years. Bhattacharya et $\mathrm{al}^{22}$ and $\mathrm{Jha}$ et $\mathrm{al}^{23}$ also reported similar findings with $66 \%$ and $73.1 \%$ of the malignant neoplasms observed beyond the age of 40 years, respectively.

Of 40 cases, 6 were borderline (15\%) and 34 (85\%) were malignant, which were similar to the observation of Maheshwari et $\mathrm{al}^{24}$ in which malignant and borderlines were 83 and $17 \%$, respectively. Studies by Siddiqui et al, ${ }^{25}$ Janaki et al ${ }^{26}$ and Ramachandran et $\mathrm{al}^{27}$ also had similar findings. In the present study, borderline tumors were all serous type 6/40 and serous cystadenocarcinomas comprised 21/40 (52\%) of cases. This was however dissimilar with Maheshwari et $\mathrm{al}^{24}$ who reported that mucinous cystadenocarcinomas constituted the largest group among malignant neoplasms.

In this study, most of the cases were bilateral 22/40 (55\%), and among them 21 cases were malignant and 1 borderline serous tumor. Right and left ovary involvement was 27.5 and $17.5 \%$, respectively. Agarwal et $\mathrm{al}^{22}$ also had similar findings with bilaterality being common in malignant tumors $(66.7 \%, 16 / 24)$. According to the study conducted by Hart, ${ }^{28} 60 \%$ of serous borderline tumors were unilateral. Out of 21 cases, 14 (66\%) of serous cystadenocarcinomas were bilateral. Fifty percent of mucinous cystadenocarcinomas were bilateral in this study. Two out of four cases were endometrioid and two out of three were clear cell carcinomas and bilateral. Boger-Megiddo et $\mathrm{al}^{15}$ also observed 57.5\% malignant serous tumors and $26.8 \%$ endometrioid carcinoma to be bilateral in another study. Among 34 malignant tumors in our study, 22 (64.7\%) were high grade and 12 (35.3\%) low grade. Pelupessy et $\mathrm{al}^{29}$ found similar findings in their study, that is, $56.7 \%$ high grade and $43.3 \%$ low-grade tumors.

In the present study, out of 34 malignant cases 21 (61.8\%) showed LVSI. Thirteen (13/21, 62\%) high-grade serous cystadenocarcinoma showed LVSI. Two out of three clear cell carcinoma and one of four (25\%) showed LVSI. As much as 33\% mucinous carcinoma showed LVSI. Chen ${ }^{30}$ et al found similar results regarding LVSI-58.5\% cases showed LVSI, and high-grade serous, clear cell carcinoma, endometrioid carcinoma, and mucinous carcinomas showed 67.1, 70.4, 20.8, and 7.8\% LVSI, respectively. Qian et $\mathrm{al}^{31}$ showed in their study that out of 96 ovarian cancer patients, 36 (54.5\%) had LVSI, which is in agreement with the present study.

In our experience, half of the cases $(17,50 \%)$ showed omental implantation from primary carcinoma and all 17 cases were malignant. Similar results were reported by Heintz et al ${ }^{32}$ where visible implants outside the pelvis constituted $60 \%$ of epithelial ovarian carcinoma cases.

CD44 staining showed 22/40 (55\%) positive cases out of 40 , which was similar to the study by Zheng et al $^{33}$ where CD44 immunoreactivity was detected in 32/50 tissue sections (64\%), but not detected in normal ovarian epithelial tissue. No borderline tumor showed CD44 expression. Sillanpaa et al found that CD44 was low to absent in normal ovarian epithelial cells, ${ }^{34}$ which is concordant with this study.

We observed CD44 positivity in $81,50,75$ and $0 \%$ cases in serous, mucinous, endometrioid and clear cell carcinomas, respectively, which was similar to the study by Zheng et al, ${ }^{33}$ where CD44 positivity were $61,77,60$ and $0 \%$ for serous, mucinous, endometrioid and clear cell carcinoma, respectively.

This study showed $100 \%$ positivity of CD44 in stage IIIc and $80 \%$ positivity in stage II, but no positive correlation was found between stage and CD44 expression. This is concordant with Bartakova et al $^{10}$ where no statistically significant correlation was found between CD44 expression and stage of the disease. Zheng et $\mathrm{al}^{33}$ found CD 44 positive in $85 \%$ cases of high-grade carcinoma which is similar to the present study where 73\% high-grade tumors show CD44 expression.

There was no significant association between status of CD44 and status of $\mathrm{p} 53$ of the tumors of the patients $(p=0.10)$. However, positivity of CD44 was found significantly higher in case of positive status of p53. Nineteen (56\%) out of 34 malignant cases showed positive p53 staining in this study, which was similar to previous studies and that of Harlozinska et $\mathrm{al}^{35}$

There was significant association between status of CD44 and status of Ki67 of the tumors of the patients with $p$ value of 0.029 ( - Fig. 4). Positivity of CD44 was found significantly higher in case of positive status of Ki67. In our study, ki67 expressed in $72.5 \%$ cases and among them 28 wear malignant and one was borderline tumor. These findings were concordant with the study by Korkolopoulou et $\mathrm{al}^{36}$ where Ki67 was overexpressed in malignant tissues compared with benign or borderline tissue. Mean Ki67 positivity in serous cystadenocarcinoma and mucinous cystadenocarcinoma were $41.64 \pm 10.15 \%$ and $40.3 \pm 8.11 \%$, respectively in a study by Sardar et al. ${ }^{37}$ Sylvia et al showed $64.3 \%$ positive cases of Ki67 expression, which is similar to our study. ${ }^{38}$

CD44, as a type of cell-surface adhesion molecules, mediates multiple pathological and physiological processes, including malignancy development, cell adhesion, angiogenesis, wound healing, and inflammation. Studies have suggested that CD44 overexpression promotes cells migration and metastasis for human solid tumors, including breast carcinoma and ovarian carcinoma. ${ }^{29,32}$ The expression pattern of CD44 in malignant cells is of great importance, since CD44 is the main receptor for hyaluronan, and the hyaluronan binding domain exists in all CD44 isoforms and CD44-HA interaction involved in tumor progression. Hence, much effort has focused in blocking the CD44-HA interaction. Although only few approaches have made it as far as clinical trials, the scientific progress in the last few years suggests strong prospects for anti-CD44 therapies.

\section{Conclusion}

The present study suggested that the levels of CD44 expression were increased in epithelial ovarian cancer compared with borderline tumor. CD44 is positively correlated with Ki67 expression and tumor grade, which can be related with tumor progression, high lymphovascular invasion and metastasis, including peritoneal deposition. Positivity of CD44 was found significantly higher in case of positive status of p53. For prognostic significance and therapeutic applications, more corroborative and multicentric works in this field are needed. CD44 can be targeted for therapy in recurrent and resistant cases of ovarian cancer. 


\section{Nature of Work and Contribution by Each Author}

Author 1 Concepts and design, data acquisition, literature search, performing laboratory tests, compilation and analysis of data, writing of manuscript, and final approval of manuscript.

Author 2 Concepts and design, collection of data, performing laboratory tests and interpretation, compilation and analysis of data, writing of manuscript, statistical analysis manuscript editing,manuscript review, and final approval of manuscript.

Author 3 Concept and design, definition of intellectual content, compilation and analysis of data, writing of manuscript, and final approval of manuscript.

\section{Financial Support and Sponsorship}

Nil.

\section{Conflicts of Interest}

None declared.

\section{References}

1 Ferlay J, Shin HR, Bray F, Forman D, Mathers C, Parkin DM. Estimates of worldwide burden of cancer in 2008: GLOBOCAN 2008. Int J Cancer 2010;127(12):2893-2917

2 Bray F, Ferlay J, Soerjomataram I, Siegel RL, Torre LA, Jemal A. Global cancer statistics 2018: GLOBOCAN estimates of incidence and mortality worldwide for 36 cancers in 185 countries. CA Cancer J Clin 2018;68(6):394-424

3 Ferlay J, Parkin DM, Steliarova-Foucher E. Estimates of cancer incidence and mortality in Europe in 2008. Eur J Cancer 2010;46(4):765-781

4 Howlader N, Noone AM, Krapcho M, Garshell J, Miller D, Altekruse SF, et al. A. SEER Cancer Statistics Review, 1975-2012. Bethesda MD: National Cancer Institute; based on November 2014 SEER data submission, posted to the SEER web site, April 2015. Available at: https://seer.cancer. gov/archive/csr/1975_2012/, April 2015. Accessed March 10, 2019

5 Chen VW, Ruiz B, Killeen JL, Coté TR, Wu XC, Correa CN. Pathology and classification of ovarian tumors. Cancer 2003; 97(10, Suppl):2631-2642

6 McCluggage WG. Morphological subtypes of ovarian carcinoma: a review with emphasis on new developments and pathogenesis. Pathology 2011;43(5):420-432

7 Mor G, Alvero A. The duplicitous origin of ovarian cancer. Rambam Maimonides Med J 2013;4(1):e0006

8 El Hafez AA. Stemness markers in ovarian cancer: nature and implications. J Cytol Histol 2014;5(3):1-2

9 Ponta H, Sherman L, Herrlich PA. CD44: from adhesion molecules to signalling regulators. Nat Rev Mol Cell Biol 2003; 4(1):33-45

10 Bartakova A, Michalova K, Presl J, Vlasak P, Kostun J, Bouda J. CD44 as a cancer stem cell marker and its prognostic value in patients with ovarian carcinoma. J Obstet Gynaecol 2018;38(1):110-114

11 Scholzen T, Gerdes J. The Ki-67 protein: from the known and the unknown. J Cell Physiol 2000;182(3):311-322

12 Goh AM, Coffill CR, Lane DP. The role of mutant p53 in human cancer. J Pathol 2011;223(2):116-126

13 Ween MP, Oehler MK, Ricciardelli C. Role of versican, hyaluronan and CD44 in ovarian cancer metastasis. Int J Mol Sci 2011;12(2):1009-1029

14 McCluggage WG, Judge MJ, Clarke BA, et al; International Collaboration on Cancer Reporting. Data set for reporting of ovary, fallopian tube and primary peritoneal carcinoma: recommendations from the International Collaboration on Cancer Reporting (ICCR) Mod Pathol 2015;28(8):1101-1122

15 Boger-Megiddo I, Weiss NS. Histologic subtypes and laterality of primary epithelial ovarian tumors. Gynecol Oncol 2005; 97(1):80-83

16 Ross JS, Sheehan CE, Williams SS, Malfetano JH Szyfelbein WM, Kallakury BV. Decreased CD44 standard form expression correlates with prognostic variables in ovarian carcinomas. Am J Clin Pathol 2001;116(1):122-128

17 Garzetti GG, Ciavattini A, Goteri G, et al. Ki67 antigen immunostaining (MIB 1 monoclonal antibody) in serous ovarian tumors: index of proliferative activity with prognostic significance. Gynecol Oncol 1995;56(2):169-174

18 Zagorianakou N, Stefanou D, Makrydimas G, et al. CD44s expression, in benign, borderline and malignant tumors of ovarian surface epithelium. Correlation with p53, steroid receptor status, proliferative indices (PCNA, MIB1) and survival. Anticancer Res 2004;24(3a):1665-1670

19 Mondal SK, Banyopadhyay R, Nag DR, Roychowdhury S, Mondal PK, Sinha SK. Histologic pattern, bilaterality and clinical evaluation of 957 ovarian neoplasms: a 10-year study in a tertiary hospital of eastern India. J Cancer Res Ther 2011; 7(4):433-437

20 Agrawal P, Kulkarni DG, Chakrabarti PR, Chourasia S, Dixit M, Gupta K. Clinicopathological spectrum of ovarian tumors: A 5-year experience in a tertiary health care center. J Basic Clin Reprod Sci 2015;4:90-96

21 Malik IA. A prospective study of clinico-pathological features of epithelial ovarian cancer in Pakistan. J Pak Med Assoc 2002;52(4):155-158

22 Bhattacharya M, Shinde SD, Purandare VN. A clinicopathological analysis of 270 ovarian tumours. J Postgrad Med 1980;26(2):103-107

23 Jha R, Karki S. Histological pattern of ovarian tumors and their age distribution. Nepal Med Coll J 2008;10(2):81-85

24 MaheshwariV,TyagiSP,SaxenaK,etal.Surfaceepithelialtumours of the ovary. Indian J Pathol Microbiol 1994;37(1):75-85

25 Siddiqui RB, Shankar BH, Khan IM. Morphological Patterns of Ovarian Neoplasms in Different Age Groups-A Center based study. PJMHS 2015;9:1139

26 Janaki M, Kumar MP, Arora VS, Harish V, Lavanya A Histopathological examination of primary ovarian tumors. Int J Res Health Sci 2015;3:217-249

27 Ramachandran G, Harilal KR, Chinnamma KK, Thangavelu H. Ovarian neoplasms-a study of 903 cases. J. Obstet. And Gynec. 1972;22:309-315

28 Hart WR. Borderline epithelial tumors of the ovary. Mod Pathol 2005;18(Suppl 2) :S33-S50

29 Pelupessy NU, Andrijono A, Sutrisna B, et al. CD133, CD44, and ALDH1A1 as cancer stem cell markers and prognostic factors in epithelial ovarian cancer. Med J Indones 2019;28:63-69

30 Chen M, Jin Y, Bi Y, Li Y, Shan Y, Pan L. Prognostic significance of lymphovascular space invasion in epithelial ovarian cancer. J Cancer 2015;6(5):412-419

31 Qian X, Xi X, Jin Y. The grading of lymphovascular space invasion in epithelial ovarian carcinoma. Int J Gynecol Cancer 2010; 20(5):895-899

32 Heintz AP, Odicino F, Maisonneuve P, et al. Carcinoma of the ovary. FIGO 26th Annual Report on the Results of Treatment in Gynecological Cancer. Int J Gynaecol Obstet 2006;95(Suppl 1): S161-S192

33 Zheng J, Wang Y, Zhao L, Zhao S, Cui M. Overexpression of CD44 and EpCAM may be associated with the initiation and progression of epithelial ovarian cancer. Int J Clin Exp Pathol 2017;10:4780-4786

34 Sillanpää S, Anttila MA, Voutilainen K, et al. CD44 expression indicates favorable prognosis in epithelial ovarian cancer. Clin Cancer Res 2003;9(14):5318-5324 
35 Harlozińska A, Bar JK, Sedlaczek P, Gerber J. Expression of p53 protein and Ki-67 reactivity in ovarian neoplasms. Correlation with histopathology. Am J Clin Pathol 1996;105(3): 334-340

36 Korkolopoulou P, Vassilopoulos I, Konstantinidou AE, et al. The combined evaluation of p27Kip1 and Ki-67 expression provides independent information on overall survival of ovarian carcinoma patients. Gynecol Oncol 2002;85(3):404-414
37 Sardar K, Singh J, Tirkey S. Ki67 immuno-expression in ovarian tumors. IOSR Journal of Dental and Medical Sciences 2018; 17:34-37

38 Sylvia MT, Kumar S, Dasari P. The expression of immunohistochemical markers estrogen receptor, progesterone receptor, Her-2-neu, p53 and Ki-67 in epithelial ovarian tumors and its correlation with clinicopathologic variables. Indian J Pathol Microbiol 2012;55(1):33-37 